\title{
Convenient synthesis of the immunogenic glycolipid BbGL1.
}

\author{
Sebastián N. Jäger, Exequiel O. J. Porta, and Guillermo R. Labadie*
}

Instituto de Química Rosario (IQUIR-CONICET), Facultad de Ciencias Bioquímicas y Farmacéuticas, Universidad Nacional de Rosario. Suipacha 531, S2002LRK, Rosario, ARGENTINA.

Corresponding author at: Instituto de Química Rosario (IQUIR-CONICET-UNR), Facultad de Ciencias Bioquimicas y Farmacéuticas, Universidad Nacional de Rosario. Suipacha 531, S2002LRK, Rosario, ARGENTINA.

Tel.: $+54-341-4370477 \# 108$

Fax: $+54-341-4370477 \# 112$

E-mail address: labadie@iquir-conicet.gov.ar.(G. R. Labadie) 


\begin{abstract}
A simple and efficient method to synthesize the immunogenic glycolipid BbGL1 is introduced. Two simple steps were required to obtain the desired product in good yield. First, a highly efficient glycosylation of cholesterol using galactosyl trichloroacetimidate as a donor was performed to produce cholesteryl- $\beta$-D-galactoside. Finally, an efficient palmitoylation on the C6-OH of the galactose of the synthesized saponin using sym-collidine and acyl chloride under microwave heating that produced BbGL1 in good yield. The procedure is a convenient and cheaper alternative to the reported procedures allowing a rapid preparation of multiple analogs and conjugates.
\end{abstract}

Keywords: Acyl steryl glycosides, BbGL1, Lyme disease, microwave heating, selective acylation. 


\section{Introduction}

Lyme disease is a "tick borne" illness that is rapidly spreading worldwide. Most of the confirmed cases are coming from the Northern hemisphere,[1] affecting mostly the United States and Europe. The Center for Disease Control and Prevention (CDC) recently reported that the number of counties in northeastern states of US with high incidence of Lyme disease increased by 320 \%.[2] In Europe there is a high incidence of the disease in Scandinavian countries and Austria, Slovenia and German.[3] The European Centre for Disease Prevention and Control have reported a steady increase in Lyme disease cases over the past two decades.[4] The main factors that are contributing to the explosive epidemic of Lyme disease are linked to failed diagnosis and inappropriate treatment of the patients. Diagnosis of Lyme disease is not precise enough[3] and treatment is very restrictive, where long-term combination antimicrobial therapy is the norm.

The etiological agent of the disease is the spirochete Borrelia burgdorferi senso lato. This bacterium has evolved to disseminate throughout mammalian hosts. Infected species of Ixodes spp ticks are responsible of the transmission of the disease to mammals, including humans.[4] Different efforts have been conducted to develop an effective vaccine against Lyme disease.[5] Unfortunately, after the withdrawal of the OspA (Outer Surface Protein A) based vaccine in 2002, no further immunization agent has been introduced on the market .[6]

Two lipids with immunogenic response has been isolated and characterized in B. burgdorferi. The compounds reported in 2001 were identified as cholesteryl 6-O-acyl- $\beta$-D-galactopyranoside (BbGL1, Figure 1) and 1,2-di-O-acyl-3-D-galactopyranosyl-sn-glycerol (BbGL2, Figure 1).[7-9] Both glycolipids have a mixture of palmitoyl and oleoyl groups and BbGL2 must contain a cisalkene to preserve the antigenicity.[10] 


\section{[INSERT FIGURE 1 HERE]}

Looking to contribute to the development of new immunogenic strategies for Lyme disease we indented to improve the exiting preparation of BbGL1. The optimized and improved synthesis including a $\beta$-selective glycosylation followed by a novel and extremely fast and efficient acylation is presented.

\section{Experimental Section}

\subsection{General}

Chemical reagents were purchased from commercial suppliers and used without further purification, unless otherwise noted. Solvents were analytical grade or were purified by standard procedures prior to use. All reactions were performed under an atmosphere of nitrogen using oven-dried glassware and standard syringe/septa techniques. Yields were calculated for material judged homogeneous by thin layer chromatography (TLC) and nuclear magnetic resonance $\left({ }^{1} \mathrm{H}\right.$ NMR). All reactions were monitored by thin layer chromatography performed on silica gel 60 F254 pre-coated aluminum sheets, visualized by a $254 \mathrm{~nm}$ UV lamp, and stained with an ethanolic solution of 4-anisaldehyde. Column flash chromatography was performed using silicagel 60 (230-400 mesh). Microwave heated reactions were conducted on a CEM Discover $300 \mathrm{~W}$. Sym-collidine was dried with sodium hydroxide lentils overnight followed by fractional distillation and stored under $4 \AA$ molecular sieves. ${ }^{1} \mathrm{H}$ and ${ }^{13} \mathrm{C}$ NMR spectra were acquired on a Bruker Avance II $300 \mathrm{MHz}(75.13 \mathrm{MHz})$ using $\mathrm{CDCl}_{3}$ as a solvent except otherwise noted. Chemical shifts $(\delta)$ were reported in ppm downfield from tetramethylsilane (TMS) at 0 ppm as 
internal standard and coupling constants $(\mathrm{J})$ are in hertz $(\mathrm{Hz})$. Chemical shifts for carbon nuclear magnetic resonance $\left({ }^{13} \mathrm{C}\right.$ NMR $)$ spectra are reported in parts per million relative to the center line of the $\mathrm{CDCl}_{3}$ triplet at $76.9 \mathrm{ppm}$. The following abbreviations are used to indicate the multiplicities: $\mathrm{s}=$ singlet, $\mathrm{d}=$ =doublet, $\mathrm{t}=$ triplet, $\mathrm{q}=$ quartet, $\mathrm{m}=$ multiplet, $\mathrm{p}=$ pentet, $\mathrm{br}=$ broad signal. Melting points were measured on an Electrothermal 9100 apparatus and are uncorrected. IR spectra were obtained using an FT-IR Shimadzu IR Prestige-21 spectrometer and only partial spectral data is listed. High resolution mass spectra were performed on a mass spectrometer. High-resolution mass spectra (ESI-HRMS) were recorded on a Bruker MicrOTofII with lock spray source.

\subsection{Chemical synthesis}

\subsubsection{Synthesis of 1,2,3,4,6-penta-O-benzoyl-D-galactose}

$\mathrm{BzCl}(33.3 \mathrm{~mL})$ was slowly added to a cooled solution (ice-water bath) of D-galactose (1.00 g; $5.6 \mathrm{mmol})$ in anhydrous pyridine $(25 \mathrm{~mL})$. Chloroform was added if no total dissolution of the galactose was observed. The mixture was stirred at $\mathrm{rt}$ overnight. TLC analysis hexane:AcOEt (1:1) shows the presence of a product with $\mathrm{Rf}=0.9$. Once the reaction is finished, $\mathrm{CHCl}_{3}(15 \mathrm{~mL})$ was added and organic solution was washed with $10 \% \mathrm{HCl}(3 \times 15 \mathrm{~mL})$. Then, combined organic extracts were washed with saturated, $\mathrm{H}_{2} \mathrm{O}$, saturated $\mathrm{NaHCO}_{3}, \mathrm{H}_{2} \mathrm{O}$ and dried with anhydrous $\mathrm{Na}_{2} \mathrm{SO}_{4}$ and evaporated under vacuum. Finally, the product was purified by flash chromatography with hexane:AcOEt gradient to obtain $3.65 \mathrm{~g}$ with an isolated yield of $93 \%$. The NMR spectra are in agreement with the reported spectra.[11] 


\subsubsection{Synthesis of $2,3,4,6$-tetra-O-benzoyl-D-galactose.}

To a solution of 1,2,3,4,6-penta-benzoyl-D-galactose $(1.93 \mathrm{~g}, 2.76 \mathrm{mmol})$ in dry $\mathrm{CH}_{2} \mathrm{Cl}_{2}(15 \mathrm{~mL})$ was added $\mathrm{HBr} / \mathrm{HOAc} 33 \%(1.6 \mathrm{~mL})$. After being stirred at room temperature for $1.5 \mathrm{~h}$, the solution was washed with saturated $\mathrm{NaHCO}_{3}$ solution and brine. The organic layer was concentrated in vacuo, and the residue was subjected to hydrolysis. The residue was dissolved in acetone $(10 \mathrm{~mL})$ and water $(1 \mathrm{~mL})$, then $\mathrm{Ag}_{2} \mathrm{CO}_{3}$ was added $(1.0 \mathrm{~g})$ portionwise. After 1 hour, the suspension was filtered through celite, the filtrate was concentrated in vacuo and the residue was purified with flash column chromatography with hexane:AcOEt gradient to obtain $1.48 \mathrm{~g}$ of the product as a white solid in $90 \%$ yield as a mixture of anomers $(\beta: \alpha, 9: 1)$. The NMR spectra are in agreement with the reported spectra.[12] On the ${ }^{1} \mathrm{H}$ and ${ }^{13} \mathrm{C}$ NMR asignation the following abvrevation: $\mathrm{Cho}=$ Cholesterol, $\mathrm{Gal}=$ Galactose and $\mathrm{Pal}=$ Palmitate

\subsubsection{Synthesis of 2,3,4,6-tetra-O-benzoyl-D-galactopyranosyl trichloroacetimidate (2)}

$\alpha / \beta-2,3,4,6$-tetra-O-benzoyl-D-galactose $(450 \mathrm{mg}, 0.75 \mathrm{mmol})$ was dissolved in anhydrous DCM $(6 \mathrm{~mL})$ and cooled at $0{ }^{\circ} \mathrm{C}$. Then, DBU $(0.21 \mathrm{mmol})$ and trichloroacetonitrile $(0.4 \mathrm{mmol})$ were added and stirred for $4 \mathrm{~h}$ were the TLC analysis (hexane/ethyl acetate 1:1) revealed absence of the starting material and the presence of two more polar products. The reaction mixture was evaporated under vacuum and directly purified by flash column with hexane:AcOEt gradient affording $488 \mathrm{mg}$ of the expected product as a yellowish oil in $88 \%$ yield. The NMR spectra are in agreement with the reported spectra.[12]

\subsubsection{Cholesteryl 2,3,4,6-tetra-O-benzoyl- $\beta$-D-galactopyranoside (3).}

Trichloroacetimidate 2 (178 mg, $0.24 \mathrm{mmol})$ and cholesterol (62 mg; $0.16 \mathrm{mmol})$ were dissolved

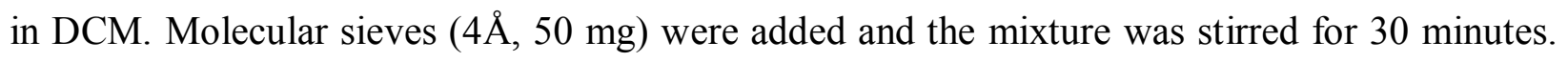
Then, $0.02 \mathrm{M}$ TMSOTf solution in DCM (12 mg TMSOTf in $0.27 \mathrm{~mL}$ of DCM) was added 
dropwise. After 10 minutes, TLC analysis (hexane/ethyl acetate 70:30) showed the absence of the trichloroacetimidates. Reaction was quenched adding triethylamine until the solutions turn yellowish and was evaporated. The crude product was purified by column chromatography hexane:AcOEt gradient providing $213 \mathrm{mg}$ of the product 3 with an isolated yield of $92 \%$. ${ }^{1} \mathrm{H}$ NMR (300 MHz, $\left.\mathrm{CDCl}_{3}\right) \delta$ 8.15-7.28 (m, 21H, OBz); 5.97 (d, H, $\left.J=3.36 \mathrm{~Hz}\right) ; 5.77$ (dd, $J_{1}=10.9$ $\mathrm{Hz}$ and $\left.J_{2}=7.9 \mathrm{~Hz}, 1 \mathrm{H}\right) ; 5.59\left(\mathrm{dd}, J_{1}=10.4 \mathrm{~Hz}\right.$ and $\left.J_{2}=3.4 \mathrm{~Hz}, 1 \mathrm{H}\right) ; 5.21(\mathrm{~d}, J=4.5 \mathrm{~Hz}, 1 \mathrm{H}$, Cho C6-H); $4.90\left(\mathrm{~d}, J=8.0 \mathrm{~Hz}, 1 \mathrm{H}\right.$, Gal C1-H); $4.67\left(\mathrm{dd}, J_{1}=10.8 \mathrm{~Hz}\right.$ and $\left.\mathrm{J}_{2}=7.0 \mathrm{~Hz}, 1 \mathrm{H}\right) ; 4.46-4.27$ (m, 1H); $4.31(\mathrm{t}, J=6.6 \mathrm{~Hz}, 1 \mathrm{H}) ; 3.62-3.49(\mathrm{~m}, 1 \mathrm{H}, \mathrm{Cho} \mathrm{C} 3-\mathrm{H}) .[13]$

\subsubsection{Synthesis of cholesteryl- $\beta$-D-galactopyranoside (4)}

To a solution of 2,3,4,6-tetra-O-benzoyl-D-galactopyranosyl 3 (150 mg, $0.2 \mathrm{mmol}$ ) in anhydrous THF:MeOH (1:1) $(8 \mathrm{~mL}), 200 \mu \mathrm{L}$ of sodium methoxide solution $(5 \mathrm{mg}$ of $\mathrm{Na}$ in $500 \mu \mathrm{L}$ of $\mathrm{MeOH}$ anhydrous) was added. The reaction was stirred at RT for $3 \mathrm{~h}$ where the TLC analysis (hexane:ethyl acetate 70:30) revealed the absence of the acetylated starting material. The presence of the product was evident running another TLC (DCM:MeOH 90:10). The reaction was quenched adding one equivalent of $\mathrm{AcOH}$ or Amberlite acid resin and evaporated under vacuum. Finally, the solid residue was purified by flash column with $\mathrm{MeOH}$ :DCM gradient affording $110 \mathrm{mg}$ of the expected product as a white solid in quantitative yield. IR $\mathrm{U}_{\max } 3446$ ($\mathrm{OH}) ; 3419$ (-OH); 3404 (-OH); 3385 (-OH); 2902 (=CH-); 2889 (=CH-); 2868 (-CH2-); 2868 (CH2-); 1664 (-C=C-) cm ${ }^{-1} .{ }^{1} \mathrm{H}$ NMR (300 MHz, DMSO-d $\left.{ }^{6}\right) \delta 5.30$ (br, 1H, Cho C6-H); 4.614.27 (m, 3H, Gal OH); 4.40 (t, $J=5.6 \mathrm{~Hz}, 1 \mathrm{H}, \mathrm{Gal} \mathrm{C}-\mathrm{H}) ; 4.15$ (m, 1H, Gal C1-H); 3.62 (bs, 1H, Gal C-H); 3.57-3.35 (m, 3H, Gal CH 2 , Cho C3-H); 0.95 (s, 3H, Cho C19-H); 0.90 (s, 3H, Cho C21-H); 0.85 (s, 3H, Cho C26-H); 0.82 (s, 3H, Cho C27-H); 0.65 (s, 3H, Cho C18-H). ${ }^{13} \mathrm{C}$ NMR (DMSO-d $\left.{ }^{6}\right) \delta 141.1$ (C, Cho C5); 121.5 (CH, Cho C6); 102.0 (CH, Gal C1); 77.6 (CH, Cho C3); 
$75.6(\mathrm{CH}, \mathrm{Gal} \mathrm{C} 5) ; 74.1(\mathrm{CH}, \mathrm{Gal} \mathrm{C}) ; 71.2(\mathrm{CH}, \mathrm{Gal} \mathrm{C}) ; 68.7(\mathrm{CH}, \mathrm{Gal} \mathrm{C}) ; 61.0\left(\mathrm{CH}_{2}, \mathrm{Gal} \mathrm{C}\right)$;

56.7 (CH, Cho C14); 56.2 (CH, Cho C17); 50.2 (CH, Cho C9); 42.4 (C, Cho C13); $39.4\left(\mathrm{CH}_{2}\right)$;

$39.0\left(\mathrm{CH}_{2}\right) ; 37.3\left(\mathrm{CH}_{2}\right) ; 36.7(\mathrm{C}$, Cho $\mathrm{C} 10) ; 36.2\left(\mathrm{CH}_{2}\right) ; 35.6(\mathrm{CH}$, Cho $\mathrm{C} 20) ; 32.0\left(\mathrm{CH}_{2}\right) ; 31.9$ $(\mathrm{CH}) ; 29.8\left(\mathrm{CH}_{2}\right) ; 28.2(\mathrm{CH}) ; 27.8\left(\mathrm{CH}_{2}\right) ; 24.3\left(\mathrm{CH}_{2}\right) ; 23.7\left(\mathrm{CH}_{2}\right) ; 23.0\left(\mathrm{CH}_{3}\right) ; 22.8\left(\mathrm{CH}_{3}\right) ; 21.1$

$\left(\mathrm{CH}_{2}\right) ; 19.5\left(\mathrm{CH}_{3}\right.$, Cho $\left.\mathrm{C} 19\right) ; 19.0\left(\mathrm{CH}_{3}\right.$, Cho $\left.\mathrm{C} 21\right) ; 12.1\left(\mathrm{CH}_{3}\right.$, Cho C18). ESI-HRMS calculated for $\mathrm{C}_{33} \mathrm{H}_{56} \mathrm{O}_{6} \mathrm{Na}^{+}[\mathrm{M}+\mathrm{Na}]^{+}$571.3969, found 571.3959.

\subsubsection{Cholesteryl (6'-O-palmitoyl)- $\beta$-D-galactopyranoside (BbGL1)}

Regioselective acylation under conventional heating conditions: Cholesteryl galactoside (90 mg, $0.17 \mathrm{mmol}$ ) was dissolved in $2.5 \mathrm{~mL}$ of sym-collidine. Then, palmitoyl chloride (71 $\mathrm{mg}, 0.26$ mmol) of were slowly added to the mixture at room temperature. After 30 minutes under continuous stirring at $160{ }^{\circ} \mathrm{C}$, the reaction was diluted with AcOEt $(10 \mathrm{~mL})$ and quenched with $10 \% \mathrm{HCl}(10 \mathrm{~mL})$. Centrifugation could improve the interface separation. The inorganic phase was extracted with AcOEt $(2 \times 10 \mathrm{~mL})$. The combined organic extracts were dried with anhydrous $\mathrm{Na}_{2} \mathrm{SO}_{4}$ and evaporated under vacuum. Finally, the purification of the crude reaction was performed by flash column with DCM:MeOH gradient affording $55 \mathrm{mg}$ of BbGL1 as a white solid with $42 \%$ yield.

Procedure for regioselective acylation under microwave heating conditions: cholesteryl galactoside (90 mg, $0.17 \mathrm{mmol}$ ) was dissolved in $2.5 \mathrm{~mL}$ of sym-collidine and palmitoyl chloride (104 $\mathrm{mg}, 0.38 \mathrm{mmol}$ ) was slowly added to the mixture at room temperature in a microwave vial, sealed, introduced in the microwave reactor and heated at constant temperature $\left(160{ }^{\circ} \mathrm{C}\right)$ for 3 min. Then, the reaction mixture was diluted with AcOEt $(10 \mathrm{~mL})$ and quenched with $10 \% \mathrm{HCl}$ $(10 \mathrm{~mL})$. Centrifugation was used to improve the interface separation. The inorganic phase was extracted with AcOEt $(2 \times 10 \mathrm{~mL})$. The combined organic extracts were dried with $\mathrm{Na}_{2} \mathrm{SO}_{4}$ 
anhydrous and evaporated under vacuum. The product was purified by column chromatography. IR $v_{\max } 3545$ (-OH), $3446(-\mathrm{OH}), 3421(-\mathrm{OH}), 3408$ (-OH); 2954 (=C-); $2933\left(-\mathrm{CH}_{2}-\right) ; 1674$ $(\mathrm{C}=\mathrm{O}) \mathrm{cm}^{-1} .{ }^{1} \mathrm{H}$ NMR $\left(300 \mathrm{MHz}, \mathrm{CDCl}_{3}\right) \delta 5.35(\mathrm{bs}, 1 \mathrm{H}, \mathrm{Cho} \mathrm{C6}-\mathrm{H}) ; 4.36-4.22(\mathrm{~m}, 3 \mathrm{H}$, Gal C6'$\left.\mathrm{H}_{2}, \mathrm{Cl}^{\prime}-\mathrm{H}\right)$; 3.89 (s, H, C4'-H); 3.74-3.44 (m, 4H, Gal C5'-H, Gal C3'-H, Gal C2'-H, Cho C3H); 2.41-2.19 (m, 4H, Pal $\mathrm{CH}_{2}-\mathrm{C}=\mathrm{O}$, Cho $\left.\mathrm{C}_{-}-\mathrm{H}_{2}\right) ; 2.09-1.73$ (m, 5H, Cho $\left.\mathrm{CH}\right) ; 1.38-1.19$ (m, 22H, Pal C-H, Cho C-H); 0.99 (s, 3H, Cho C19-H); 0.92 (s, 3H, Cho C21-H); 0.89 (s, 3H, Cho C26-H), 0.87 (t, $J=7.2 \mathrm{~Hz}, 3 \mathrm{H}, \mathrm{Pal} \mathrm{CH} 3) ; 0.85$ (br, 3H, Cho C27-H); 0.67 (s, 3H, C18-H). ${ }^{13} \mathrm{C}$ NMR $\left(\mathrm{CDCl}_{3}\right) \delta 173.7(\mathrm{C}=\mathrm{O}$, Pal C=O); $140.4(\mathrm{C}$, Cho $\mathrm{C} 5) ; 122.1(\mathrm{CH}, \mathrm{Cho} \mathrm{C6}) ; 101.6(\mathrm{CH}$, Gal C1); $79.6(\mathrm{CH}$, Cho C3); $73.4(\mathrm{CH}, \mathrm{Gal} \mathrm{C} 3) ; 72.4(\mathrm{CH}, \mathrm{Gal} \mathrm{C} 5) ; 71.4(\mathrm{CH}, \mathrm{Gal} \mathrm{C} 2) ; 68.6$ (CH, Gal C4); 62.9 ( $\mathrm{CH}_{2}$, Gal C6); $56.8(\mathrm{CH}$, Cho C14); $56.2(\mathrm{CH}$, Cho $\mathrm{C} 17) ; 50.1(\mathrm{CH}, \mathrm{Cho}$ C9); 42.3 (C, Cho C13); $39.8\left(\mathrm{CH}_{2}\right) ; 39.5\left(\mathrm{CH}_{2}\right) ; 38.8\left(\mathrm{CH}_{2}\right) ; 37.3\left(\mathrm{CH}_{2}\right) ; 36.7(\mathrm{C}$, Cho $\mathrm{C} 10)$; $36.2\left(\mathrm{CH}_{2}\right) ; 35.8(\mathrm{CH}, \mathrm{Cho} \mathrm{C} 20) ; 34.3\left(\mathrm{CH}_{2}, \mathrm{Pal} \mathrm{C}\right) ; 31.9\left(\mathrm{CH}_{2}\right) ; 31.8(\mathrm{CH}) ; 30.3\left(\mathrm{CH}_{2}\right) ; 29.8$ $\left(\mathrm{CH}_{2}\right) ; 29.7\left(\mathrm{CH}_{2}\right) ; 29.4\left(\mathrm{CH}_{2}\right) ; 29.3\left(\mathrm{CH}_{2}\right) ; 28.2\left(\mathrm{CH}_{2}\right) ; 28.0(\mathrm{CH}) ; 25.0\left(\mathrm{CH}_{2}\right) ; 24.3\left(\mathrm{CH}_{2}\right) ; 23.9$ $\left(\mathrm{CH}_{2}\right) ; 22.8\left(\mathrm{CH}_{3}\right.$, Cho $\left.\mathrm{C} 27\right) ; 22.7\left(\mathrm{CH}_{2}\right) ; 22.6\left(\mathrm{CH}_{3}\right.$, Cho $\left.\mathrm{C} 27\right) ; 21.1\left(\mathrm{CH}_{2}\right) ; 19.4\left(\mathrm{CH}_{3}\right.$, Cho C19); $18.7\left(\mathrm{CH}_{3}\right.$, Cho $\left.\mathrm{C} 21\right) ; 14.1\left(\mathrm{CH}_{3}, \mathrm{Pal} \mathrm{CH}\right) ; 11.9\left(\mathrm{CH}_{3}\right.$, Cho C18). ESI-HRMS calculated for $\mathrm{C}_{49} \mathrm{H}_{86} \mathrm{O}_{7} \mathrm{Na}^{+}[\mathrm{M}+\mathrm{Na}]^{+}$809.6266, found 809.6266.

\subsubsection{Cholesteryl- $\beta$-D-galactopyranoside recovery from early polyacylated fractions.}

The polyacylated steryl glucosides formed during the reaction were recovered from the early fractions of the flash column chromatography during ASG purification. After evaporation, the obtained solid was submitted to methanolysis to produce free cholesteryl- $\beta$-Dgalactopyranoside. $100 \mathrm{mg}$ of the solid obtained after the evaporation of the early fractions of the chromatography mentioned above (rich in polyacylated cholesteryl- $\beta$-D-galactopyranoside) were dissolved in anhydrous THF:MeOH (1:1) $(5 \mathrm{~mL})$ and $200 \mu \mathrm{L}$ of sodium methoxide solution (5 
mg of $\mathrm{Na}$ in $500 \mu \mathrm{L}$ of $\mathrm{MeOH}$ anhydrous) were added. After 3h at RT, TLC analysis (hexane/ethyl acetate 70:30) shows the absence of the acetylated starting material. On the other hand, the presence of the product was observed by TLC in a highly polar mobile phase (DCM:MeOH 90:10). The reaction was then quenched with an equivalent amount of AcOH or amberlite acid resin. The solvent was evaporated and the crude product directly purified by flash column chromatography with DCM:MeOH gradient.

\section{Results and discussion}

There are three different reported synthesis of BbGL1 in the literature. Pozsgay et al,[14] reported a complex 13 steps synthetic pathway requiring different protection-deprotection steps. Later, Kulkarni et al [15] developed a simpler approach using per-O-TMS galactosyl iodide on the key glycosylation step, that unfortunately provided a mixture $\alpha / \beta$ anomers in a 1:9 ratio. The critical regioselective acylation was performed through a Steglich palmitoylation implementing a very slow addition of the reagent to obtain the desired product with $43 \%$ yield from the saponin. Finally, Grindley and coworkers [16] synthesized a library of one of the two Lyme disease antigens in four steps from $\mathrm{D}$-galactose using $\mathrm{BF}_{3}$-promoted glycosylation of the peracetate to prepare the cholesteryl- $\beta$-glycoside and TBTU-promoted esterification to regioselectively acylate the galactose $\mathrm{C6}-\mathrm{OH}$ with different fatty acids. This glycosylation methodology uses an additional acetylation step to separate the anomeric mixtures and to purify the product from the remaining cholesterol.

With those precedents in mind, we wanted to simplify and improve the synthesis. We selected the trichloroacetimidate glycosylation as the first coupling step. Peracetylated galactose was selected as the glycosyl donor, based on its commercial availability and being better than others

from the atom economy point of view. The trichloroacetimidate was easily obtained in high yield 
from commercial peracetylated galactose. Unfortunately, the glycosylation with TMSOTf in DCM produced a mixture of the orthoformiate, acetylated cholesterol and the expected $\beta$ galactoside. Different conditions were tested, changing the addition order, temperature and stoichiometry without improving the galactoside yield over $38 \%$. Nevertheless, that reaction had very good regiocontrol, providing exclusively the $\beta$-product, being an improvement over Kulkarni et al synthesis.[14] Based on that positive outcome, we opted to change the glycosylation to the methodology reported by Deng et al,[17] where a well-known and efficient glycosylation reaction was used. That reaction was performed using benzoyl protected glycosyl trichloroacetimidate as donor, cholesterol as acceptor and TMSOTf as activating agent. In our hands, the galactosyl trichloroacetimidate was easily prepared from the galactose in two steps following a reported procedure.[18] The acetimidate 2 happened to be quite stable; no showing decomposition after being stored at room temperature for more than 3 months. As reported by Deng,[17] the coupling reaction was completed within $15 \mathrm{~min}$, providing the expected benzoylated saponin 3 in excellent yield (90\%). No benzoyl group transferred product or ortho esters were detected. The newly formed glycosidic bond was proved to be exclusively 1,2-trans based on their ${ }^{1} \mathrm{H}$ NMR spectra. It should be noted that although the vast evidence of great potential, selectivity and high yields of this methodology, the last publications connected with the BbGL1 synthesis did not take advantage of that efficient procedure.[14,15] Once the $\beta$-glycosidic bond was formed, the methanolysis of the benzoylated product provided the cholesteryl- $\beta$-galactoside 4 quantitatively after flash chromatography purification. (Scheme 1)

[INSERT SCHEME 1 HERE] 
Having completed the glycoside preparation, we moved to the critical acylation step. That reaction requires a very selective method to esterify the primary alcohol in the presence of the secondary alcohols of the galactose. Conventional acylations are achieved mainly using acyl chloride as acylating agents and pyridine as a base.[19] Those reactions generally provide mixtures of primary and secondary alcohol esterification products that are very difficult to isolate with high purity.[20,21] Those reactions are usually conducted using stoichiometric amounts of the base and dichloromethane as a solvent. Alternatively, bases can be used as solvents, being more adequate for dissolving highly polar substrates. Temperature is another critical factor to achieve the expected selectivity. Apart from those, different methodologies have been reported to improve the yield and selectivity of the sterylglycoside acylation.[14,15] Paczkowski et al reported [22] a regioselective enzymatic procedure using immobilized lipases. The reaction catalyzed by Candida antarctica selectively acylate the C6-OH of steryl glucoside with fatty acids, but yields are higly dependent of the fatty acid used. On the other hand, our group has recently reported a regioselective and protective group free esterification reaction of steryl glucosides.[23] The reaction use collidine as a solvent and using acyl chloride as acylating agent.(Scheme 2).

[INSERT SCHEME 2 HERE]

The sterically hindered base has a double role, is the perfect solvent for the steryl glycoside and provides the required selectivity. Initially, the reaction on galactoside 4 was performed under conventional heating. After 30 minutes at $160^{\circ} \mathrm{C}$, all the starting material have been reacted, but 
more than one product was formed. (Scheme 2) The reaction provided the expected C6palmytoylated cholesteryl galactoside as main product together with a mixture of di- and tripalmitoylated products. The mixture was easily separated by column chromatography providing BbGL1 in $42 \%$ yield. The poly-palmitoyl- galactosyl cholesterol by-products were also isolated, recovering the starting cholesteryl- $\beta$-galactoside by reaction with sodium methoxide in methanol in $54 \%$ yield. (Scheme 2) As we previously reported for the C6-acylation of cholesteryl glucoside, the best yield of the monoacylated product was achieved when 1.5 equivalents of the acylating agent were used. [23]

Looking to shorten the reaction time, we tested used microwave heating, being able to complete the reaction in 3 minutes. This is remarkable improvement of the selective acylation reported strategies that can even run for days to achieve selectivity.[14,15]

The optimized preparation of BbGL1 is presented on the Scheme 3. The global yield of the synthesis starting from galactose was $57 \%$ (considering the recovered starting cholesteryl galactoside on the acylation step). This is the first synthesis which combines the simple and highly efficient glycosylation using the tricloroacetimidate galactosylation and the hindered base directed selective microwave accelerated acylation to conveniently obtain the immunogenic bacterial glycolipid BbGL1.

\section{[INSERT SCHEME 3 HERE]}

\section{Conclusions}

In conclusion, we have successfully developed a new synthesis of BbGL1 combining an efficient galactosylation using the tricloroacetimidate donor and an efficient acylation. The key acylation step was performed using microwave accelerated conditions where the selectivity was 
accomplished using sym-collidine as a base with and strict control of the stoichiometry. The synthesis requires simple reagents allowing a rapid, highly efficient and regioselective preparation of the Cholesteryl (6'-O-palmitoyl)- $\beta$-D-galactopyranoside in $57 \%$ yield staring from galactose. The efficient synthetic route of BbGL1 can be applied to prepare new derivatives for future biological studies.

\section{Acknowledgements}

The authors wish to express their gratitude to UNR (Universidad Nacional de Rosario), Fundación Josefina Prats, CONICET (Consejo Nacional de Investigaciones Científicas y Técnicas, PIP 2009-11/0796 and PIP 2012-14/0448), Agencia Nacional de Promoción Científica y Tecnológica (PICT-2011-0589). GRL is member of the Research Career of CONICET. SNJ and EOJP thanks CONICET for the award of a fellowship.

\section{References}

[1] A. Smith, J. Oertle, D. Prato, Chronic Lyme Disease: Persistent Clinical Symptoms Related to Immune Evasion, Antibiotic Resistance and Various Defense Mechanisms of Borrelia burgdorferi. Open J. Med. Microbiol. 4 (2014) 252-260. DOI: 10.4236/ojmm.2014.44029.

[2] K.J. Kugeler, G.M. Farley, J.D. Forrester, P.S. Mead, Geographic distribution and expansion of human Lyme disease, United States. Emerg Infect Dis. 8 (2015) 1455-1457. DOI: $10.3201 /$ eid2108.141878.

[3] U. Koedel, V. Fingerle, H.-W. Pfister, Lyme neuroborreliosis - epidemiology, diagnosis and management, Nat. Rev. Neurol. 11 (2015) 446-456. DOI: 10.1038/nrneurol.2015.121. 
[4] ECDC, Lyme borreliosis in Europe, (2017).

[5] M.E. Embers, S. Narasimhan, Vaccination against Lyme disease: past, present, and future, Front. Cell. Infect. Microbiol. 3 (2013). DOI: 10.3389/fcimb.2013.00006.

[6] H. Sprong, T. Azagi, D. Hoornstra, A.M. Nijhof, S. Knorr, M.E. Baarsma, J.W. Hovius, Control of Lyme borreliosis and other Ixodes ricinus-borne diseases, Parasites and Vectors. 11 (2018) 1-16. DOI: 10.1186/s13071-018-2744-5.

[7] H. Hossain, H.J. Wellensiek, R. Geyer, G. Lochnit, Structural analysis of glycolipids from Borrelia burgdorferi, Biochimie. 83 (2001) 683-692. DOI: 10.1016/S03009084(01)01296-2.

[8] G. Ben-Menachem, J. Kubler-Kielb, B. Coxon, A. Yergey, R. Schneerson, A newly discovered cholesteryl galactoside from Borrelia burgdorferi, Proc. Natl. Acad. Sci. 100 (2003) 7913-7918. DOI: 10.1073/pnas.1232451100.

[9] N.W.J. Schröder, U. Schombel, H. Heine, U.B. Göbel, U. Zähringer, R.R. Schumann, Acylated Cholesteryl Galactoside as a Novel Immunogenic Motif in Borrelia burgdorferi Sensu Stricto, J. Biol. Chem. 278 (2003) 33645-33653. DOI: 10.1074/jbc.M305799200.

[10] V. Pozsgay, J. Kubler-Kielb, B. Coxon, A. Marques, J.B. Robbins, R. Schneerson, Synthesis and antigenicity of BBGL-2 glycolipids of Borrelia burgdorferi, the causative agent of Lyme disease, Carbohydr. Res. 346 (2011) 1551-1563. DOI: 10.1016/j.carres.2011.04.045.

[11] C. Gallo-Rodriguez, O. Varela, R.M. De Lederkremer, One-pot synthesis of $\beta$-D-Galf(1 $\rightarrow 4)[\beta$-D-Galp $(1 \rightarrow 6)]-D-G l c N a c$, a "core" trisaccharide linked O-glycosidically in glycoproteins of Trypanosoma cruzi, Carbohydr. Res. 305 (1997) 163-170. DOI: 10.1016/S0008-6215(97)00256-5. 
[12] W. Pilgrim, P. V. Murphy, $\mathrm{SnCl}_{4}$ - and $\mathrm{TiCl}_{4}$-catalyzed anomerization of acylated O - And S -glycosides: Analysis of factors that lead to higher $\alpha$ : $\beta \mathrm{d}$ reaction rates, J. Org. Chem. 75 (2010) 6747-6755. DOI: 10.1021/jo101090f.

[13] B.N.A. Mbadughat, F.M. Menger, Sugar/Steroid/Sugar Conjugates: Sensitivity of Lipid Binding to Sugar Structure, Org. Lett. 5 (2003) 4041-4044. DOI: 10.1021/o1030084r.

[14] V. Pozsgay, J. Kubler-Kielb, B. Coxon, G. Ekborg, Synthesis of two glycolipid antigens of the causative agent of Lyme disease, Tetrahedron. 61 (2005) 10470-10481. DOI: 10.1016/j.tet.2005.08.053.

[15] S.S. Kulkarni, J. Genvay-Hague, Two-step synthesis of the immunogenic bacterial glycolipid BbGL1, Org. Lett. 10 (2008) 4739-4742. DOI: 10.1021/o1801780c.

[16] J.D.A.K. Twibanire, R.P. Omran, T.B. Grindley, Facile synthesis of a library of lyme disease glycolipid antigens, Org. Lett. 14 (2012) 3909-3911. DOI: 10.1021/ol301697c.

[17] S. Deng, B. Yu, J. Xie, Y. Hui, Highly efficient glycosylation of sapogenins, J. Org. Chem. 64 (1999) 7265-7266. DOI: 10.1021/j0990603x.

[18] R.S. Lankalapalli, A. Baksa, K. Liliom, R. Bittman, Synthesis and properties of a photoactivatable analogue of psychosine ( $\beta$-galactosylsphingosine), ChemMedChem 5 (2010) 682-686. DOI: 10.1002/cmdc.201000018.

[19] E. Kaji, T. Komori, M. Yokoyama, T. Kato, T. Nishino, T. Shirahata, Efficient synthesis of the functional central core lactides, a constituent of antibiotic fattiviracins, Tetrahedron 66 (2010) 4089-4100. DOI: 10.1016/j.tet.2010.04.007.

[20] T. Kawabata, W. Muramatsu, T. Nishio, T. Shibata, Y. Uruno, R. Stragies, Regioselective acylation of octyl $\beta$-D-glucopyranoside by chiral 4-pyrrolidinopyridine analogues, Synthesis (2008) 747-753. DOI: 10.1055/s-2008-1032176. 
[21] W.F. Li, L.R. Chen, X.J. Gong, Z.N. Li, K.K. Li, Synthesis of esters of ginsenoside metabolite M1 and their cytotoxicity on MGC80-3 cells, Molecules 18 (2013) 3689-3702. DOI: 10.3390/molecules18043689.

[22] C. Paczkowski, A. Musial, L. Wlodkowski, M. Kalinowska, Z.A. Wojciechowski, Lipasecatalyzed regioselective synthesis of steryl (6'-O-acyl) glucosides, Biotechnol. Lett. 29 (2007) 1403-1408. DOI: 10.1007/s10529-007-9400-z.

[23] S.N. Jäger, M. Mittelbach, R. Cabrera, G.R. Labadie, Simple method for high purity acylated steryl glucosides synthesis, Eur. J. Lipid Sci. Technol. 118 (2016) 827-833. DOI: 10.1002/ejlt.201500205. 

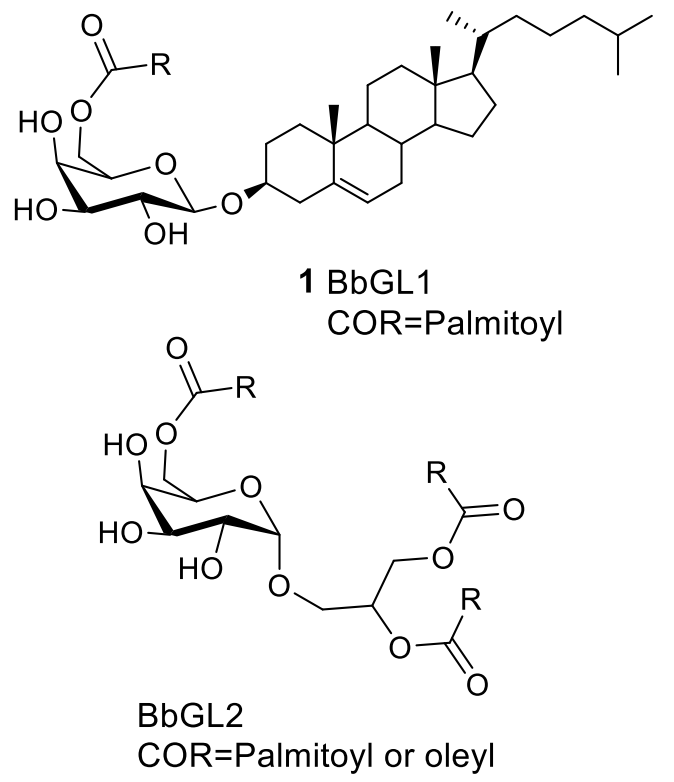

Figure 1. Borrelia burgdorferi glycolipid antigens. 


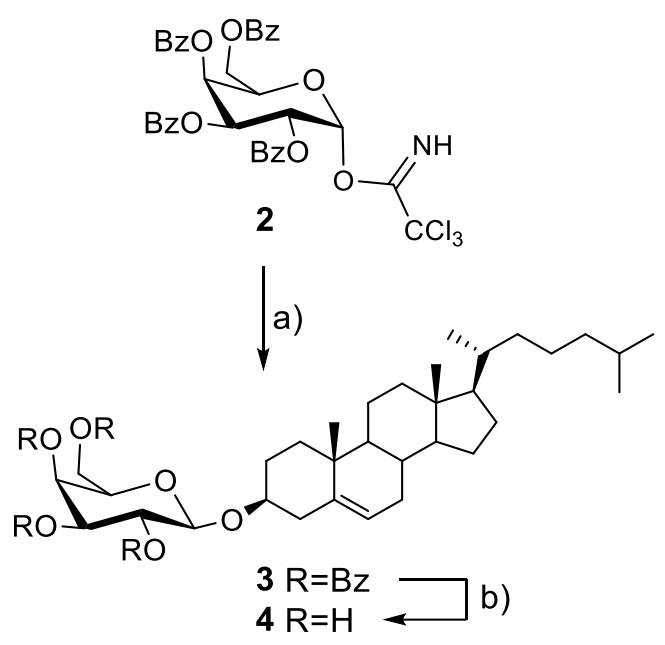

Scheme 1. Galactosylation reaction. Reagents and conditions a) 1-Cholesterol TMSOTf, DCM, $90 \%$ b) $\mathrm{NaOMe} / \mathrm{MeOH}$, quantitative. 


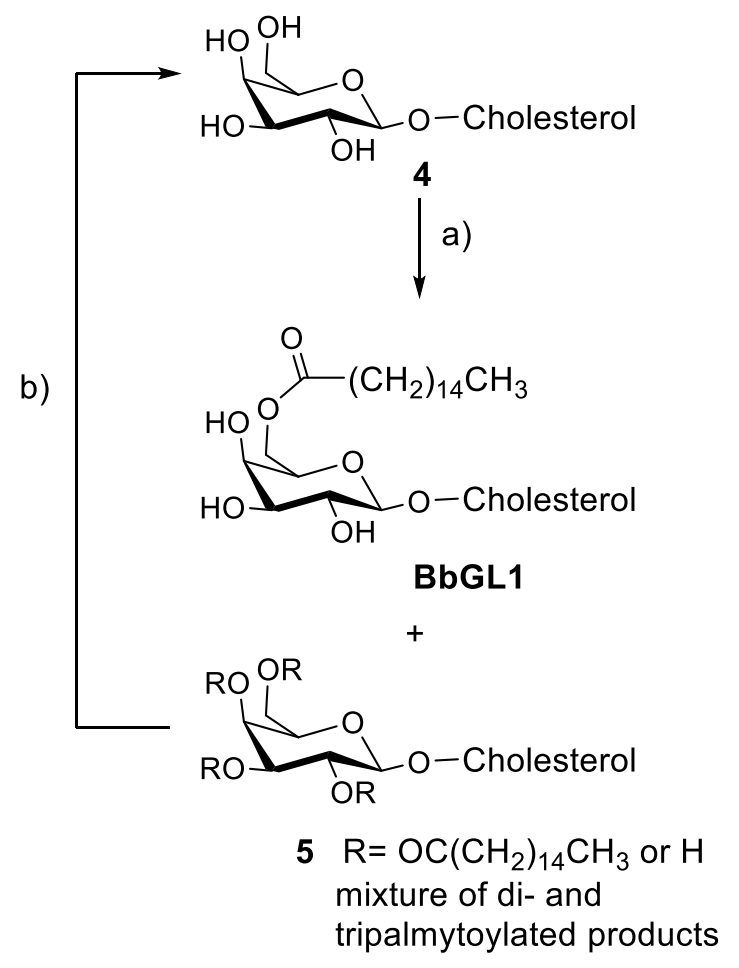

Scheme 2: Palmitoylation of cholesteryl- $\beta$-galactoside and recycling of by-products. Reagents and conditions: a) $\mathrm{CH}_{3}\left(\mathrm{CH}_{2}\right){ }_{14} \mathrm{COCl}$, sym-collidine, $160{ }^{\circ} \mathrm{C}, 30$ min.; b) $\mathrm{NaOMe}, \mathrm{MeOH}, \mathrm{RT}, 10$ $\min , 54 \%$ of the starting material 4 . 


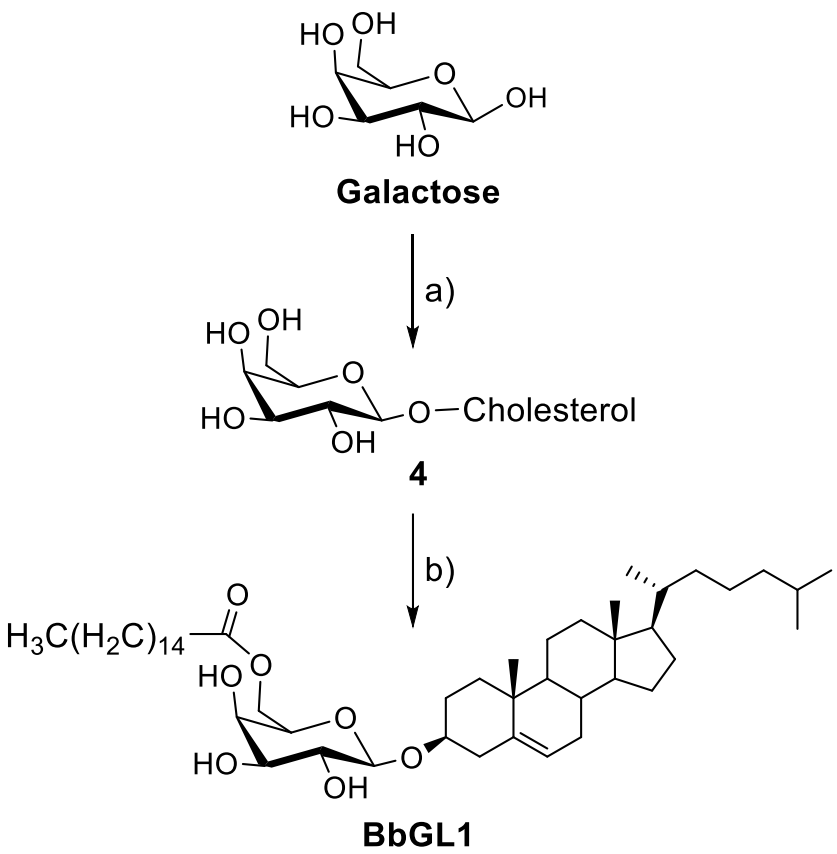

Scheme 3. BbGL1 synthesis. a) $1-\mathrm{BzCl}, \mathrm{Py}, \mathrm{O}{ }^{\circ} \mathrm{C}$ to room temp., overnight, $93 \%$; $2-33 \%$ $\mathrm{HBr} / \mathrm{HOAc}, \mathrm{DCM}, 90 \mathrm{~min}, 90 \%$; 3- trichloroacetonitrile, DBU, DCM, O ${ }^{\circ} \mathrm{C}, 88 \%$; 4 Cholesterol, TMSOTf, DCM; 2.- NaOMe, MeOH, RT, 10 min, $92 \%$ for the two steps; b) $\mathrm{CH}_{3}\left(\mathrm{CH}_{2}\right)_{14} \mathrm{COCl}$, collidine, $160{ }^{\circ} \mathrm{C}, \mathrm{MW}, 3 \mathrm{~min}, 42 \%(91 \%$ based on the recovered cholesteryl galactoside). 